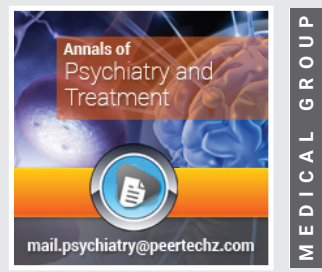

\title{
Experience of psychoactive substance use in patients with psychiatric disorders
}

\section{Barbara Gouget-Para ${ }^{1,2 *}$, Alice Deschenau ${ }^{3}$, Jean- Charles Leblanc ${ }^{4}$, Armelle Seiler ${ }^{2}$, Fathia Djellil' ${ }^{2}$, Valérie Cerboneschi ${ }^{2}$ and Muriel Lascaux ${ }^{1}$}

${ }^{1}$ IED-University Paris 8, 2 rue de la Liberté, Saint-Denis, France

${ }^{2}$ GH Paul-Guiraud, Camille Claudel Unit, Rue Andras Beck, Clamart, France

${ }^{3} \mathrm{GH}$ Paul Guiraud, Pole Addictions, 54 avenue de la République, Villejuif, France

${ }^{4}$ Food and Agriculture Organization of the United Nations (FAO), Rome, ITALY

Received: 17 December, 2019

Accepted: 20 March, 2020

Published: 21 March, 2020

*Corresponding author: Dr. Barbara Gouget-Para, IED-University Paris 8, 2 rue de la Liberté, Saint-Denis, France, E-mail: barbarapara@acomplice.fr

Keywords: Addictions; Comorbidity; Dual pathology; Psychotic symptoms; Subjective experience; Grounded theory

https://www.peertechz.com

\section{Check for updates}

\section{Abstract}

A dual pathology is the coexistence of a psychiatric disorder and an addiction in the same patient. Between 30 and $50 \%$ of patients currently admitted to psychiatry in Europe would suffer from a dual pathology. The interaction between two mental illnesses can lead to a different clinical picture of the clinical pictures of each of the pathologies taken separately and may require new therapeutic strategies. The aim of this study was to better understand the decompensation or relapse of a dual pathology.

Based on a mixed quantitative and qualitative approach by grounded theory, adult patients hospitalized in psychiatry were asked about their subjective experience of the use of psychoactive substances. The sample consisted of sixteen patients, dependent on at least one psychoactive substance (tobacco excluded) and classified according to their psychiatric pathology: troubles of the schizophrenia spectrum, mood and personality disorders (respectively 7,5 and 4 patients).

Results showed that therapeutic dimension of motivation to consume predominates hedonic and social dimensions, especially in schizophrenic patients. Although perceiving adverse effects of drugs, patients have the perception that their consumptions satisfy their expectations of products, especially in terms of appeasing their suffering. Most patients do not wish to enter a weaning process. Results suggested that decompensation of a dual pathology is often associated with a change in substance use, an acutization of psychotic experiences and an unfavorable social and emotional context that puts patients in critical condition requiring hospitalization in psychiatry.

\section{Introduction}

Substance use can induce psychiatric disorders and/ or have an impact on psychiatric pathologies. In individuals with an established psychotic disorder, for instance, cannabis exacerbates psychotic symptoms and has negative consequences on the course of the disease [1]. Cannabis use modifies the psychiatric symptoms of schizophrenic patients by reinforcing their anxiety and depressive symptoms [2]. In general, positive [3] and negative symptoms of schizophrenia -including social impairment [4], -are increased by substance use.
However, drug use is a common phenomenon in psychiatric patients. The prevalence of substance use disorders in schizophrenic patients varies between $30 \%$ and $90 \%$ depending on the study (including smoking). Use disorders are also particularly common in bipolar patients: one in three bipolar patients has a drinking disorder and more than $7 \%$ of bipolar patients have a cannabis use disorder [5].

Psychiatric patients apparently seek in their consumption therapeutic, social and hedonic effects in connection with their pathological symptoms [6-14]. Patients suffering from a dual pathology, and in particular schizophrenia coupled with 
addiction, have little awareness of their pathology and perceive more beneficial effects from their consumption than negative complications and the counter-effects of drugs.

The decompensation factors are multiple and the clinical pictures poorly defined, making the diagnosis of dual pathologies complex. Integrative care is still insufficient today. Few studies investigate the diversity of dual pathologies, taking into account all (poly)substance use and the variety of psychiatric disorders

Experiential approaches referring to the subjective narrative of individuals are very rarely implemented in Francophone research, yet they can lead to a better understanding of these pathologies and enrich clinical practices to improve the management of patients according to a psychotherapeutic approach. From the subjective experience of the use of psychoactive substances in adult patients hospitalised in psychiatric units, the objective of this research was to better understand the decompensation or relapse of a dual pathology.

The psychotropic experience, as lived through by the subject, contains essential knowledge about the way in which subjects live and perceive their discomfort (disorders) and how they try to compensate (manage) them. Feelings associated with drug use - whether positive or negative-play a fundamental role in consumer behaviour.

An Australian team has looked into the experiential experience of cannabis use in healthy subjects [15]. Cannabis consumers with a high score on the schizotypal personality questionnaire reported significantly more psychotic-type experiences during consumption (e.g. suspicion and paranoid traits, a fear of going crazy, auditory hallucinations, disturbed thoughts, or feelings of depersonalisation). The study also reported dysphoric phenomena such as anxiety, nervousness, depressive symptoms, or sadness [16].

Costain [17], implemented a phenomenological interpretative approach to study the effects perceived by schizophrenic patients following their cannabis use. The patients interviewed testified to their strong belief in the usefulness of cannabis. They explained why they were continuing to use it. They believed that cannabis helped them to hear "voices" more clearly, to control their symptoms to increase their energy levels, to improve their cognitive functions, to forget their childhood trauma, and could be an answer to persecution. The author also showed that patients were not very aware of the origin of their disorders. According to him, this poses two problems: the first is posed to the caregivers when the diagnosis is made; the second involves patients complying well with their treatment.

A Swiss team asked schizophrenic patients about the causal link between their cannabis use and their schizophrenia [18]. Team members explored the patients' beliefs and perceptions about the effects of cannabis. The results show that the patients did not establish a causal Link: they did not recognise the existence of a dual pathology. On the contrary, they considered their use as therapeutic support and reported that the beneficial effects of cannabis (decreased anxiety and nervousness) outweigh its negative effects (exacerbation of the positive symptoms of schizophrenia).

Recently, a South African team confirmed the results published by Buadze [18], but using a quantitative approach [19]. These authors questioned 60 schizophrenic patients during their hospitalisation, investigating their past and present cannabis use (that is during their hospitalisation); their motivations and perceived effects; and their perceptions of a possible link between their consumption and their psychiatric illness. More than $60 \%$ of patients were aware of their psychiatric illness. Ninety-five per cent of them admitted to having used cannabis in the past and $20 \%$ still admitted to consuming it at the time of the research. More than half of patients believed that cannabis had had deleterious effects on their disease. Only $26 \%$ mentioned a causal link with their decompensation, not because of their use of cannabis, but because of their use of other illicit substances. Twenty-six per cent of patients believed that only poor quality cannabis can trigger schizophrenia. Forty-eight per cent thought that only excessive cannabis use can be responsible for schizophrenia. Most participants reported beneficial effects of cannabis: they perceived an improvement in mood, relaxation, relief of boredom, reduced tension, better quality of sleep, decreased anxiety, decreased energy gain and, to a lesser extent, fewer auditory hallucinations. Nearly one-third of them believed that they derive more benefit from their cannabis use than negative counter-effects.

Thus, although some schizophrenic patients are aware that their use of cannabis can have deleterious effects on their psychiatric illness, most perceive this consumption as predominantly positive.

The experiential approach describes psychoactive experiences in patients with psychiatric illness. It brings elements of understanding to the decompensation of a dual pathology.

The purpose of the present research was to interview patients with a mental disorder during psychiatric hospitalisation. The interview focused on their subjective experience with psychoactive substances during the pre-hospitalisation period, and about the link they made between their symptoms and their consumption.

We were guided by three specific lines of questioning geared to research objectives. (1) What are the motives of consuming patients? What are their expectations of products in relation to their pathological symptoms? (2) What effects do they feel when consuming? Do their psychotropic experiences meet their consumption expectations and do they perceive associated adverse effects? (3) What beliefs have they constructed with respect to what led them to (re)hospitalisation in a psychiatric facility? Do patients make any connection between decompensation or the relapse of a dual pathology and their consumption? 


\section{Method}

Based on a mixed quantitative and qualitative approach, adult patients hospitalized in psychiatry were questioned about their experiences with the use of psychoactive substances.

\section{Methodology}

For qualitative methodology, a version of the constructivist grounded theory [19], was conducted [20], where the researcher followed a process of 'constant comparison', a significant characteristic of the grounded theory approach. Constant comparison involves initial line-by-line coding of the data followed by further more abstract coding to capture themes within the transcripts, allowing researchers to become sensitized to similarities and differences within the data.

The collection of quantitative data was done using a battery of tests. To evaluate tobacco dependence, the 'Heaviness of Smoking Index' (HSI) was used [21]. HSI represents the score of questions 1 (delay between waking up and the first cigarette) and 4 (number of cigarettes per day) of the simplified version of the Fagerström test for nicotine dependence in its second version. This test is validated in French. Quick to use clinically, its psychometric properties are limited [22]. The risk of alcohol dependence was assessed using the 'alcohol use disorders' test [23]. This test, validated in French, has good psychometric qualities [24]. The severity of cannabis use (grass, hashish or oil) was assessed by the French 'cannabis abuse screening test' [25]. This test has acceptable psychometric qualities [26]. The evaluation of a possible addiction to another substance (drugs or medicines consumed outside the medical prescriptions) was estimated thanks to the index according to the criteria of the DSM-5 [27].

Substance use motivation was evaluated by the 'reasons for use substance' questionnaire [9]. The RFUS questionnaire is composed of 5 subscales evaluating motivations for dealing with negative symptoms, motivations for a positive reinforcement, social motives, motivations in terms of conformity and acceptance, and motivations for relief. The RFUS questionnaire, in its English version, is not validated. However, as it has been used on psychotic patient populations [6], it is retained for the study.

An abbreviated 14-item version of the 'cannabis experience questionnaire' was used $[15,28]$. The CEQ is composed of 3 subscales: psychotic experiences experienced during consumption or at the end of the effect of the product or products, pleasant or unpleasant experiences, side effects. This questionnaire is validated in its English version on a population of cannabis users. Its internal consistency is very good [29]. Tests that do not exist in French have been translated by our research team.

\section{Recruitment}

Participants were recruited from a psychiatric hospital in France. The researcher visited the six units of the hospital and presented the study to stabilized inpatients (outgoing patients) known to consume psychoactive substances. Patients were provided with written information about the study and a consent sheet which they were asked to sign if they wished to participate. Recruitment was therefore a self-selecting process based on informed consent.

For those patients who consented to take part in the study, a mutually convenient time was arranged for the interview to take place. Interviews were held in a private, quiet room at the hospital where the participant was being treated. In order to ensure that patients were well enough to take part, the researcher consulted with qualified staff members at the time of consent and immediately prior to interview. At the end of the interview, the participant was asked to certify permission for their interview data to be used.

\section{Development of the interview schedule and data collec- tion}

To obtain a corpus of qualitative data aimed at better understanding patients' expectations of consumption behavior, their personal experiences during and after consumption and their possible links between addiction prior to acute crisis decompensation that leads to hospitalization in a psychiatric unit (that is to say the link they make between their consumption and their symptoms), a semi-structured interview was developed (Table 1). Sixteen interviews lasting 54 minutes on average were carried out and audio taped.

\section{Table: Interview schedule.}

1. What problems led to your hospitalization? How could you describe them?

$2 . \quad$ What do you think triggers these problems?

3. During the last 3 months before hospitalization, what led you to consume?

4. Do you consume according to the state in which you feel?

5. What are the effects that you feel while you consume?

6. How did you feel at the end of the product effect?

In the period of 3 months before hospitalization, did the effects of the product change? if so, how?

Has your psychological state of the last 3 months before hospitalization been affected by the consumption of the product? If yes, how?

9. Do you think that your consumption affects your physical health?

10. You may have heard that there is a link between substance use and the likelihood of developing mental illness later on. What do you think?

\section{Data analysis}

Interview data were transcribed verbatim and analyzed by the first author. The interviews were codified using the 'NVivo11 for windows' software (QSR International). For each of the transcripts, the data were read over several times. Detailed notes were made line by line of thoughts and interpretations of meaning both relating to the immediate data and in comparative terms with other the other transcripts. The transcripts were first analyzed using a process called open coding. This involves going through each line, capturing meaning and comparing data instances for similarities and differences. While open coding was taking place, the researcher 
wrote memos that detail thoughts that arise regarding the analysis, for example, emerging concepts or links to existing theories. After the initial stage of open coding was complete, these codes were then compared, grouped and lifted into core categories, which attempted to capture what was happening in the data (i.e., axial coding). Core categories were given conceptual definitions, therefore moving them beyond mere descriptors to more specific analytic units. These core categories were built into conceptual/theoretical models and theories by using memos made to link them to each other and the existing literature. Throughout the process, the researcher kept extensive field notes, and these were used to direct and guide the analysis.

The quantitative data were processed from the $\mathrm{R}$ open source software ( $R$ R.2.2) regarding inferential analyzes. Results present means and standard deviations.

\section{Reliability and validity}

The reliability and validity of the research was addressed implicitly. The use of memos and a reflexive diary aimed to evidence and track the progression of the analysis leading to the development of the theory. Data saturation was deemed to have been reached when no new theories or sub-theories were evident. The methodology of this research was approved by the French research ethics committee of protection of the people Nord-Ouest III (Caen, France).

As was discussed above, the initial aim of this study was to understand the expectations about the products consumed, the effects felt during psychotropic experiences, and the beliefs built about the link between psychoactive substance use and decompensation or relapse according to patients' pathological symptoms.

We hypothesized that (1) patients, particularly patients with schizophrenia, would consume more drugs for therapeutic reasons than for hedonic and social reasons; (2) outside the period of crisis leading to hospitalization, drug consumption would lead to different perceptions of psychic and/or somatic effects depending on the mental pathology of which patients suffer; (3) all patients would not make the link between the consumption of psychotropic drugs and mental pathology; their level of recognition of the dual pathology would depend on the mental pathology they suffer from.

\section{Results}

\section{Participants}

Sixteen participants took part in the study. Twelve of the participants were male and four were female. The ages of the participants varied $(38.9 \pm 14.3,[22-63])$, as did their diagnosis of psychiatric mental disorder as provided by their consultant psychiatrist (as defined by the DSM-5; APA, 2013) [27].

Three groups of disorders were differentiated within this research: (i) a group consisting of patients with schizophrenia spectrum disorders consisting of 4 patients with paranoid schizophrenia, 2 patients diagnosed with undifferentiated schizophrenia, and one patient with a schizoaffective disorder; these patients were hospitalized following a psychotic decompensation, often after break in treatment and anxious recrudescence; (ii) a group of patients with disorders with a major mood component: 4 patients were hospitalized for a moderate or severe depressive episode without psychotic symptoms, with depressive symptomatology often accompanied by suicidal ideation; another patient had a bipolar disorder with hypomanic episode: he was hospitalized following a clastic crisis at home; (iii) a group of patients with personality disorders (one patient had a dissocial personality, 3 others had an unspecified personality disorder); they were hospitalized for behavioral problems or hetero-aggressive ideas. The distribution of patients in the sample is presented in Table 2.

Table 2: Age, gender per groups of disorders of the participants of this research. \begin{tabular}{|l|l|l}
\hline Diagnostic group & Age & Gender
\end{tabular}

7 schizophrenia spectrum disorders

4 paranoid schizophrenia

2 undifferentiated schizophrenia

23-59] 1 female, 6

1 schizoaffective disorder

5 disorders with a major mood component

4 moderate or severe depressive episode

without psychotic symptoms

1 bipolar disorder with hypomanic episode

4 personality disorders

- 1 dissocial personality

males

3 unspecified personality disorder

2 females, 3 males

1 female, 3 males

\section{Abuse and dependence in psychiatric population}

To understand the dual pathology of patients in the study population, we determined their types and levels of abuse and dependence on psychoactive substances, according to their psychiatric pathologies. Of the 16 patients included in the sample, all responded to the addiction assessment questionnaires. The clinical sample showed a great diversity of psychoactive substances consumption at different levels of abuse or dependence.

Figure 1 presents the levels of dependence, addiction or risk related to the use of substances, according to the diagnostic group of patients. The problem level of addictive behavior varies from 0 to 2 . At 0 , it is considered that there is no addiction of smoking; low or no risk drinking or no consumption of alcohol; no cannabis use; no addiction to another substance or no other consumption. At 2, it is considered that there is strong dependence on tobacco; probable dependence on alcohol; high risk related to cannabis use; severe addiction related to the consumption of another substance.

Schizophrenic patients of the sample were more likely to be addicted to tobacco $(\mathrm{p}=0.019)$ and cannabis $(\mathrm{p}=0.048)$ than to other substances (excluding alcohol). Their level of alcohol dependence was lower than the risk associated with cannabis use $(p=0.020)$. Patients with a mood disorder experienced more alcohol dependence than schizophrenic patients $(\mathrm{p}=0.018)$. In case of personality disorder, addictions were varied (alcohol, cannabis and other substances). Besides, thirteen of the sixteen 
patients in the sample were poly-users with substance use at problematic levels.

\section{Products expectations}

Quantitative data: Fifteen of the 16 patients of the sample responded to the RFUS assessment questionnaire. Figure 2 shows the mean scores obtained by patients on the usemotivational questionnaire for each subscale, according to their pathology.

Whatever their pathology, the motivation to cope with negative symptoms was more important than other motivations. In schizophrenic patients, higher scores were obtained between patients' willingness to cope with negative symptoms and other types of motivation (social reasons: $\mathrm{p}=0.035$, conformity and acceptance: $\mathrm{p}=0.031$, relief: $\mathrm{p}=0.036$ ). Their consumption motives related to a positive reinforcement were higher than the motives related to seeking relief $(p=0.036)$.

Qualitative data: The meaning that patients gave to their consumption took on different aspects that intermingle. It could be a search for pleasure or a greater well-being (search for a hedonic potential); search for relief of internal suffering or self-medication (search for a therapeutic potential) or looking for social benefits such as wanting to build an identity (search for social potential). Whatever the mental pathology and the type of substance for problematic use, patients reported all hedonic, therapeutic and social motivations.

Mixed approach: To provide a cross-tabulation of the qualitative and quantitative data analyzes, a correspondence between the quantitative data obtained through the RFUS scales and the qualitative data was proposed (Table 3).

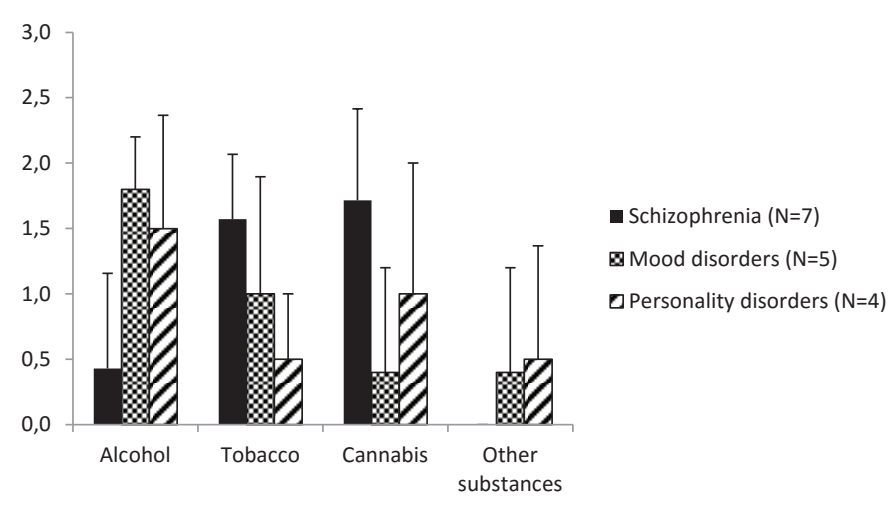

Figure 1: Levels of dependence (means and standard deviations, $\mathrm{N}=$ number of subjects).

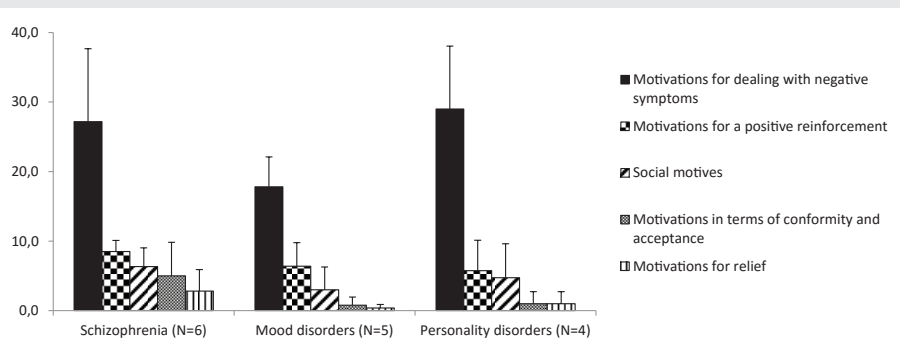

Figure 2: Motivation scores (means and standard deviations, $\mathrm{N}=$ number of subjects).
Table 3: Correspondence table between scales and categories for products expectations.

Quantitative data : RFUS scales

Qualitative data: types of motivations

Positive reinforcement

Hedonic

Negative symptoms, relief

Therapeutic

Social motives, conformity and acceptance Social

For all pathologies combined, the motivation most frequently mentioned by patients in their use experiences belongs to the dealing with negative symptoms motivation scale, while the relief scale was the one for which the scores were the weakest. The therapeutic motivation, which uses these two scales, prevailed only on one of the two scales of the RFUS questionnaire. Patients were more concerned with mitigating the consequences of their pathological symptoms such as sleep disturbances and anxiety, existential boredom, rather than seeking a calming of their psychotic symptoms.

Our first hypothesis is thus confirmed.

\section{Felt effects, outside the crisis period}

Experiences of consumption were questioned over the period of the three months preceding hospitalization, which could be considered as a 'normal' period of consumption, that is to say outside the period of crisis that lead to hospitalization in psychiatry.

To know if the effects felt by the patients during the 'normal' period of consumption corroborate their expectations regarding the products, the patients were questioned about their subjective experience of consumption. Both quantitative (CEQ questionnaire) and qualitative approaches were confronted.

Quantitative data: Fourteen of the 16 patients in the sample responded to the CEQ questionnaire. Figure 3 presents the different types of experiences reported by patients according to their pathology.

All patient groups reported experiences on each of the three scales of the CEQ questionnaire. In connection with their consumption, they said they have lived psychotic-type experiences (worry, feeling mad, mistrust, hallucinations); experiments on the scale of pleasure: experiences that could be described as hedonic (stimulation, well-being) and therapeutic (better abilities to understand the world); experiments on the scale characterizing side effects (feeling of wanting nothing to do, difficulty concentrating).

Qualitative data: The effects perceived by the patients of their psychotropic experiences made it possible to distinguish the positive effects, the negative counter-effects and the absence of perceived effects or effects perceived as neutral on one side and the psychic effects from the somatic effects on the other side.

In all pathologies, most patients perceived positive effects on their consumption. These positive effects were mostly psychic. Hedonic effects were very present in patients' speech. Drugs were perceived as stimulating and psychotropic experiences were experienced as pleasurable experiences. Therapeutic 


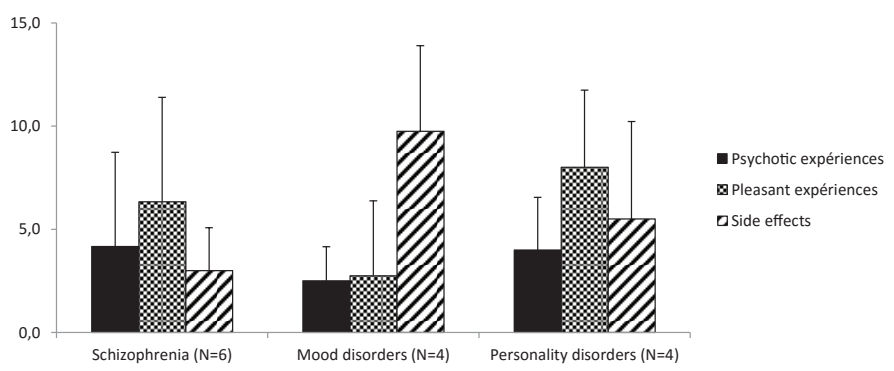

Figure 3: Levels of proven experience (means and standard deviations, $\mathrm{N}=$ number of subjects)

effects were also frequently cited, mainly in terms of decreased anxiety or sleep induction. Four schizophrenic patients reported other positive feelings, which were their psychotic experiences. One of them perceived the use of substance as a facilitator in his social interactions. Outside the crisis period, the effects felt did not differ from one group of disorders to another.

The perceived positive effects were associated with adverse effects (negative or neutral counter-effects), both somatic (state of physical lack, asthenia, memory and sleep and behavioral disorders) and psychic (psychic state of lack, withdrawal syndrome and addiction, mood alteration). The four schizophrenic patients who reported positively felt psychotic experiences, perceived them simultaneously as negative consequences of drugs. In the 'normal' period of consumption, addiction-related side effects were mostly masked (denial of dependence) or counterbalanced by most patients' beliefs about their ability to manage their consumption and the lack of will to abstinence.

Thus, in the 'normal' period of consumption (that is to say beyond the period of crisis that leads to their hospitalization), although perceiving adverse drug effects such as cognitive disorders, a change in mood or phenomena of dependence, patients had the perception that their consumption satisfied the expectations that they had from products, related to their pathological symptoms. Positive effects corroborated their expectations of mitigating the consequences of their pathological symptoms such as sleep disturbances and anxiety, but were also associated with other expectations, such as hedonic effects, the facilitation of social interactions and psychotic type experiences. The adverse effects associated with drug use and the negative consequences of drugs seldom led to abstinence in these patients. At best, patients were willing to manage their consumption and believed in their ability to do so. In times of crisis, patients did not show or showed little motivation for change (denial or slight ambivalence).

At this stage, we can conclude that our second hypothesis is confirmed.

\section{Awareness of dual pathology}

What beliefs had built patients on what led them to (re) hospitalization in psychiatry? Did patients make a connection between a decompensation or relapse of a psychiatric pathology and their consumption? Did they identify other factors associated with dual pathology?
All groups of patients reported having felt the need to increase their consumption, in terms of frequency or intensity of catches, in the crisis period preceding hospitalization. Their consumption patterns might have changed, often due to a decrease in the effect of the substance. Other patients had changed substance or turned to more problematic polydrugs. Some had noted the emergence of a new, sometimes devastating, drug effect just prior to hospitalization. In hospital, four schizophrenic patients and one patient diagnosed with a personality disorder said they continued to consume.

Beyond this need to increase their consumption, other causes, states, experiences or significant events were associated with the pre-hospitalization period. Patients in our sample, who were classified in the schizophrenia spectrum disorder group, were frequently hospitalized after an anxious recrudescence. Patients with mood-majority disorders were usually hospitalized after a moderate or severe depressive episode. At the level of perceptions, patients, any pathology combined, perceived a major alteration of their emotional state. The themes of a multiplication of worries, a major stress, a deep anxiety or even a depressive syndrome with asthenia and suicidal ideas had been mentioned.

In the pre-hospitalization period, psychotic-type experiences were experienced by both schizophrenic patients and patients with a mood disorder. Only schizophrenic patients reported invasive hallucinations during pre-hospitalization. No psychotic symptom was however specified during the diagnosis of depressive episodes.

Life events or elements from a particular socio-economic context that made some patients go into critical condition requiring hospitalization in psychiatry were most often reported. There were frequent periods of unemployment or financial hardship, a difficult environment (living in disadvantaged neighborhoods or squats); interpersonal difficulties (family conflicts for example). Relational breakdowns, current or past emotional deprivation, the illness of a loved one, bereavement, isolation, loneliness, boredom were all factors mentioned by patients. At the professional level, were sometimes implicated an accident at work or a burnout. Several patients reported their fears of a 'plugged future' or an existential crisis that would have brought them into this situation.

Thus, when they recall the period of crisis that led to their hospitalization in psychiatry, patients evoked additional psychosocial and emotional factors of their increase in drug use. Psychotic-type experiences persisted and turned into invasive hallucinations in schizophrenic patients. They were also present in patients with a mood disorder.

Three schizophrenic patients said they ignored the causes of their hospitalization. These were the only three patients in the sample not to have increased their drug use before the crisis period. All patients with a mood or personality disorder reported the emergence of psychosocial factors during the prehospitalization period. Only two of the seven schizophrenic patients did not relate to these factors. All patients with a mood disorder experienced a major alteration of their emotional 
state prior to hospitalization. Most schizophrenic patients (5 out of 7) and two patients with mood disorders also had this same perception. Only one patient of the schizophrenic group did not evoke any experience of psychotic type at any time. He was the only patient in the group without schizophrenia but a schizoaffective disorder. All other patients reported psychotic-type experiences: either they had become significant or invasive during the pre-hospitalization period, or they were evoked only in the 'normal' period of consumption. Finally, five patients found it difficult to recognize the existence of dual pathology when the eleven others believed in the link between their consumption and their mental pathology.

\section{These last results tend to confirm hypothesis 3}

Analysis of the data culminated in the development of an interpretative theory featuring beliefs that patients had built on what led them to (re)hospitalization in psychiatry. A map illustrating the theory of dual pathology and showing the inter-related nature of the categories is provided in Figure 4.

Patients perceived and experienced the period of hospitalization in three different ways.

Scenario 1: Patients identified psychosocial and sometimes emotional triggers during the pre-hospitalization period and experienced psychotic experiences as a result of increased psychotropic intake. They had difficulty recognizing the existence of their dual pathology. The time of prehospitalization and hospitalization did not leave them the possibility to become aware of it. Hospitalization was for them as an emergency intervention that allowed them to get out of the crisis, such as 'extinguishing a fire', without allowing a work of development.

Scenario 2: Patients identified psychosocial and sometimes emotional triggers in the pre-hospitalization period. Most of the time, they experienced psychotic experiences as a result of their increase in psychotropic intake. The link between their consumption and their mental pathology became possible. Hospitalization could enable them to develop and put into action.

Scenario 3: Patients could identify psychosocial and emotional triggers during the pre-hospitalization period. They lived psychotic type experiences following their increase in psychotropic intake. They managed to make the link between their consumption and their mental pathology, although they remained ambivalent on the period of hospitalization. The period of hospitalization was for them lived as a time of reflection that offered them the opportunity to become aware of their dual pathology and its setting in sense. In this situation, patients reported benefiting from hospitalization, which translated into wellness, avoidance of pain and decrease in symptoms. They conceived hospitalization as a period of rest they enjoyed and would like to continue. At the same time, the theme of forced hospitalization was frequently mentioned in these patients' speeches. Some patients continued their consumption within the hospital itself or planned to resume it in post-hospitalization. Patients therefore remained subject to their defense mechanisms.

The distribution of patients in each scenario is given in Table 4 .

A majority of schizophrenic patients (5 out of 7) managed to recognize the link between their consumption and the decompensation or relapse of their pathology. All the patients in the sample with a personality disorder made the link between their consumption and their hospitalization in psychiatry. Patients diagnosed with a mood disorder were divided and three of the five patients on the panel had difficulty understanding the link. Patients hospitalized in psychiatry developed beliefs related to use and psychosocial and emotional factors to make sense of their decompensation or relapse of their dual

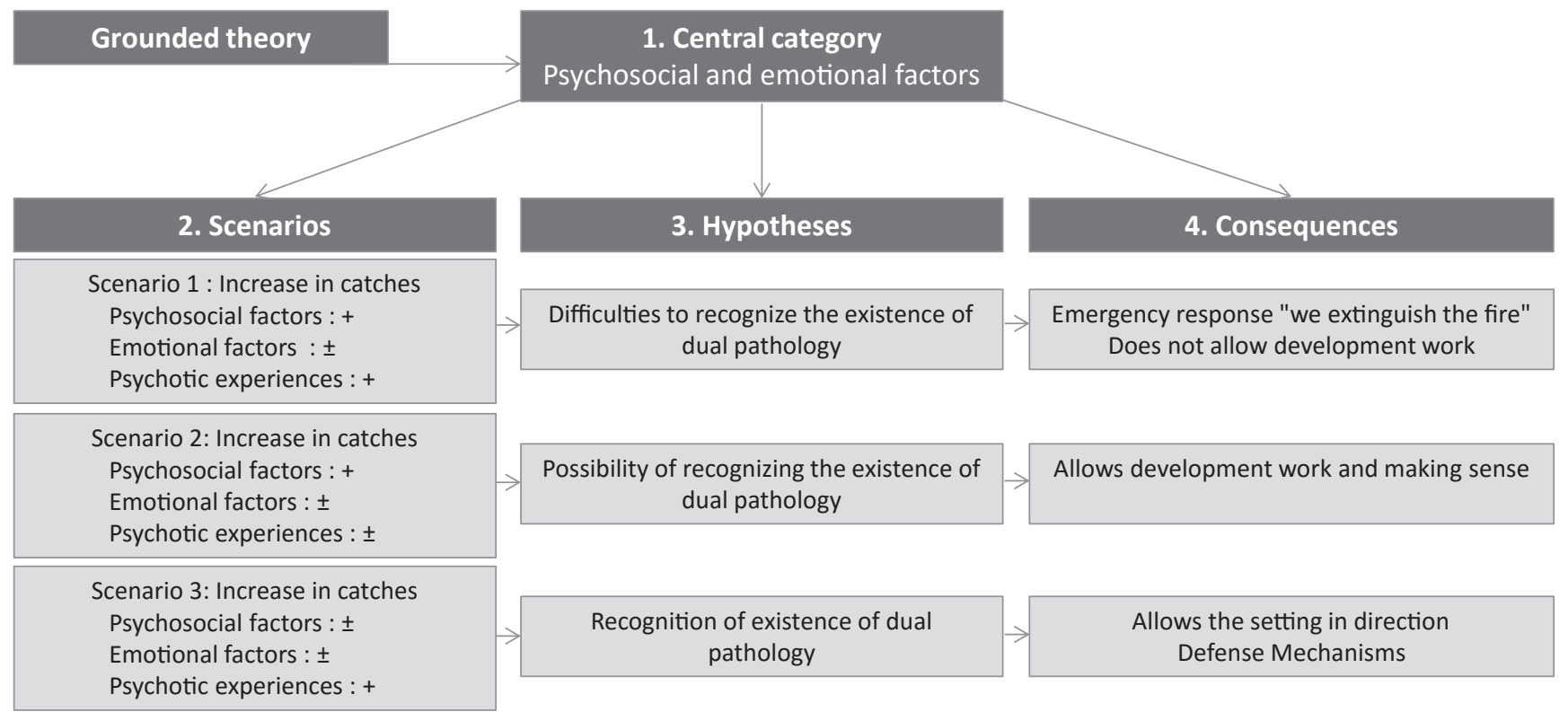


Table 4: Distribution of patients in each model scenario of the dual pathology

\begin{tabular}{|c|c|c|c|}
\hline Scenarios & Schizophrenias & $\begin{array}{c}\text { Mood } \\
\text { disorders }\end{array}$ & $\begin{array}{c}\text { Personality } \\
\text { disorders }\end{array}$ \\
\hline $\begin{array}{l}\text { 1: Emergency response, does not allow } \\
\text { development work }\end{array}$ & & 3 & \\
\hline 2: Allows elaboration and making sense & 2 & & \\
\hline $\begin{array}{l}\text { 3: Allows the setting in sense but defense } \\
\text { mechanisms }\end{array}$ & 5 & 2 & 4 \\
\hline
\end{tabular}

pathology. Hospitalization could enable them to develop and put into action.

\section{Discussion}

The interpretation of results focuses on the most innovative aspects of this research and on the question of better understanding the decompensation or relapse of a dual pathology in order to improve treatment during hospitalisation.

\section{Consumer motivations}

Regardless of the mental pathology and the type of problem substance, patients reported hedonic, therapeutic and social motivations. This corroborates the results of the literature $[12,30]$. Patients consumed drugs in search of feelings of letting go (hedonic motives) and to help them in their interpersonal relationships (social motives), but their main motivation - particularly among patients with schizophrenia - was therapeutic. These results confirm those published by Spencer et al. in 2002 and by Kolliakou, et al. in 2015 [6] Through their consumption of psychoactive substances, patients suffering from a mental illness sought to soothe their suffering in connection with the related symptoms. Beyond the initial reasons of consumption, the addiction then evolves on its own account: the therapeutic aspect is then confused with the avoidance of signs of withdrawal. For example, patients often believed that they were using cannabis like a sleeping pill, while they were actually suffering from insomnia due to withdrawal. Bergeret $[301,32]$, states that drugs calm the anxiety of fragmentation in the psychotic patient, to palliate the lability of moods or the instability in patients suffering from an antisocial personality, or to counter a depressive component in a patient with a mood disorder. Our results showed an interesting nuance in schizophrenic patients. For them, the drugs were consumed more to compensate for the negative symptoms of their pathology than their positive (psychotic) symptoms. This point also highlights the difficulty that schizophrenic patients have in distinguishing hedonism and medication from their negative symptoms, which may also be reinforced by sedation and other neuropsychological side effects of treatment.

\section{Perceived effects of consumption}

The effects felt in relation to consumption and outside crisis periods did not differ according to the patients' mental pathology.

\section{Drug self-medication}

Most patients perceived adverse effects associated with their drug use, such as cognitive impairment, mood modification or addiction. Although being aware of these adverse effects, patients had the impression that their consumption was meeting their expectations of such products, especially in terms of calming their suffering. They believed the drugs had positive therapeutic effects on them. Addiction behaviour was experienced as safety rituals that aim to secure patients' anxieties. The drugs were consumed for the purpose of selfmedication following symptoms related to their pathologies. For most patients, the subjective benefit/risk balance remained positive.

\section{Resistance to change}

Most patients hospitalised for mixed addictive and psychiatric problems continued to consume during and after hospitalisation, and did not wish to enter a withdrawal process. The counter-effects of drugs rarely induced in these patients a desire for abstinence. Some patients denied their addiction. In some cases, patients were willing to manage their use and believed in their ability to do so. Cassidy and his colleagues [33], had already observed this phenomenon. Despite a diagnosis of psychosis or dual pathology, drug users wanted to manage their consumption rather than stopping it completely. Beyond the perceived negative effects of drugs, the positive effects perceived by patients were at the heart of mechanisms of resistance to change their addiction.

\section{Therapeutic non-compliance}

The desire to continue their consumption shows how patients may be more subject to their own systems of care than those imposed medically, which could call into question drug treatments. Drugs interfere with pharmacotherapeutic treatments [34]. In schizophrenic patients, consumption may lead to a break in treatment [35] and increases the rate of rehospitalisation $[36,37]$. Breaking out is a major risk factor for relapses [38]. Consumption therefore has a major impact on the medical management of psychiatric pathologies.

Thus, with this population, an addictological approach based on abstinence is not very motivating. Support based on the goal of more rational consumption may be more efficient. In clinics, it is not uncommon to observe that during the patient support process, patients themselves realise that they cannot manage to control their consumption or that the latter still impacts their pathology. They then express a desire to stop completely. For a number of patients, limited consumption depending on the substance concerned - may not unbalance their psychiatric disorder.

\section{Therapeutic alliance and adherence to care}

One of the keys to improving adherence to care is the therapeutic alliance. Studies in the literature are consistent in demonstrating the deleterious effects of a weak therapeutic alliance on the prognosis, mortality, morbidity and cost of psychiatric pathology. The therapeutic alliance is the key to the prognostic improvement of this population. It promotes therapeutic compliance, disease management and even family support. Communication in the caregiver-patient relationship could also be an essential point for a patient's adherence to his/ 
her treatment [39]. Patients could develop a perception of the caregivers' interest in different settings, such as the amount of time caregivers spend listening to their concerns. The therapeutic alliance between caregivers and patients suffering from a psychiatric illness should therefore be increasingly sought in order to improve the climate of trust between them.

\section{Expert patient}

Rather than seeing the therapeutic relationship as a relationship between a caregiver and his/her patient, it would be better to consider it as a meeting between two experts. The patient is the expert on what works for him/her, whether it is medicated care and/or drug use. The caregiver is the expert on what has worked for other patients. This meeting between two experts should be a more respectful meeting, which would restore to the patient a feeling of efficiency. The caregiver and patient would then seek together the best, most realistic and most motivating solution to alleviate the suffering of the patient, and to adjust the therapeutic aid based on the patient's own perception of his/her needs. The reasons for change must come from the patient. The caregiver must explore the patient's ambivalence between change and the pursuit of consumption. The caregiver can thus find the patient's motivation and work to modify or amplify it. This notion joins the concept of therapeutic "permissiveness" that allows patients to regain some control of their existence by seeking the best for themselves, and to feel comfortable with who they are [40]. For Pringuey, "to care in psychiatry is to preserve a minimum field of freedom with regard to the subject, the first condition of an authentic alliance" (p. 585)

\section{Motivation for change and motivational interviewing}

Motivational interviewing aims to increase the patient's motivation to change. The emergence of motivation to change goes hand in hand with recognition of the disease and the need to heal. It passes beforehand by a reflection on ambivalence to change and requires a "decisional balance" between the advantages and disadvantages of current behaviour. This type of brief psychotherapeutic intervention is based on a collaborative relationship between the caregiver and the patient based on empathic listening, recognition and respect for resistance, the caregiver seeking to support the patient's feeling of selfefficacy. The caregiver opposes any form of pressure or guilt that might increase resistance [41]. Motivational interviewing is particularly recommended for patients with problematic resistance to change in addictions [42] and for patients for whom treatment and care require active participation but whose compliance may be weak [41]. Motivational interviewing has been shown to be effective in engaging patients in care [42]. A motivational approach to the management of dual pathologies has been successfully tested in a group of schizophrenic patients who are heavy users of cannabis [43]. It could be a preferred avenue for patients suffering from a dual pathology.

\section{Major stress as triggering factor of a dual pathology?}

To make sense of their decompensation or relapse of their dual pathology, patients hospitalised in psychiatric units construct their own beliefs related to drug use and additional psychosocial and emotional factors. Among the elements observed during the pre-hospitalisation period, patients have reported modified substance use, an activation of psychotictype experiences, changed affective states or even life events or elements from a particular social context which make them switch to a critical condition requiring hospitalisation in a psychiatric ward. These results overlap with many works in the literature $[4,13,44,45]$. We chose, from our observations, to discuss the place of stress in triggering a dual pathology.

The place of stress in a patient's life is a preclinical and retrospective item of data important in the occurrence of a dual pathology. The major role of stress in the use of substances related to a mental pathology has already been observed. A model for regulation of effects by substance use in schizophrenic patients - including stress factors - has already been proposed. The "addiction cycle" shows how, in general, drug use initially represents an immediate strategy for dealing with disruptions triggered by a significant stressful experience [46]. This strategy is unsuitable when it leads to a state of crisis in the short or medium term. In the case of mixed addictive and psychiatric disorders, major stress could be associated with the onset of a crisis. A psychoeducation of therapeutic stress management techniques could be beneficial for this population [47].

\section{Awareness of dual pathology}

The theoretical model of the subjective experience of a dual pathology has made it possible to establish the scenarios through which patients give meaning to their hospitalisation. Not all patients make the connection between the consumption of psychotropic drugs and a mental pathology. Their level of recognition of a dual pathology depends in part on the mental illness they suffer from.

\section{Insight failure}

The lack of awareness of a mental disease is mainly implicated in schizophrenic pathologies and to a lesser extent in patients with mood disorders $[48,49]$. This lack of insight goes hand in hand with the difficulty of perceiving a therapeutic benefit [50], which could then be further sought in addictive behaviour. In our sample, this lack of insight is observed more frequently in patients with mixed addictive and mood disorders. This low level of awareness of a dual pathology in patients with a mood disorder may be a defence strategy against their depressive decompensation [51]. A correlation has been shown between the level of awareness of the disease and the presence of depressive manifestations in a population of patients suffering from schizophrenia [52].

\section{Sense of coherence}

Patients hospitalised in a psychiatric unit have exceeded the threshold of psychological vulnerability that attests to good mental health. Our study showed that, for the sake of balance, they verbalised the positive reasons for their consumption. They said they wanted to continue their consumption while managing it, for purposes of therapeutic self-medication, in search of improved well-being. They also demonstrated 
their ability to make sense of their hospitalisation. They therefore sought to find a 'sense of coherence' [53-55]. The three determinants of health are the 'comprehensibility' of the situation, which reduces the stress of different events; 'manageability', that is the ability of subjects to mobilise resources to cope; and 'meaningfulness' -he ability to make sense of a problematic situation. It seems essential to offer psychotherapeutic support to these patients to accompany them in their work of conceiving, verbalising and constructing meaning.

\section{Limitations}

At the sampling level, although we were able to interview sixteen patients, this represents a small number of subjects per diagnostic group. In addition, only a population of known consumers or consumers identified by the health care team was considered. Although emerging from the state of crisis, some patients were still delusional at the time of the interview: this may be a bias for such a study on perceptions. The constitution of the diagnostic groups can pose question, none of them being exclusive. The distinction between the causes of hospitalization and the associated diagnosis could have been the subject of another relevant classification of patients. At the methodological level, the data could not benefit from a double quotation to guarantee the rigor of the analysis. They are the product of the subjective interpretation of a single researcher, not confronted with that of other more experienced researchers. In terms of research prospects, analyzes could be refined by specifically evaluating the insight and the quality of life of the patients suffering from a dual pathology [50].

\section{Conclusions}

In conclusion, this research revealed new elements related to the episodes of crisis which lead to a relapse or decompensation of a dual pathology. These episodes that lead patients to hospitalisation in psychiatric units provide a working opportunity for clinicians. The expectations and perception of consumption experiences play an important role in the aetiology of dual pathologies. Patients suffering from a dual pathology have exceeded the threshold of psychic vulnerability that attests to good mental health. Despite their lack of insight, they seek to regain a 'sense of coherence' by creating beliefs related to their drug use and psychosocial and emotional factors. These are all levers in risk reduction strategies.

How can a therapist gear his interventions to the needs of patients suffering from a dual pathology? Our results highlight the need for a good evaluation of addictive behaviour in psychiatric patients and of psychiatric disorders in addicted patients. There is a need to question the dynamics between the two issues: should patients be encouraged to consider matters once the disorders have been clearly identified? Clinicians could help open up a space (in terms of place, time and framework) for reflection and thus foster the emergence of a new meaning of the situation that could be used by patients as a protective factor. Therapists could guide patients in their abilities to mobilise their resources and focus on developing their adaptive skills and restoring their empowerment.
The need to improve the monitoring of addictions according to WHO recommendations in order to achieve integrated, complementary and coordinated care of these patients by psychiatric and addictology's teams in psychiatric hospitals is underlined.

\section{References}

1. Radhakrishnan R, Wilkinson ST, D'Souza DC (2014) Gone to pot-A review of the association between cannabis and psychosis. Frontiers in Psychiatry 5: 1-24. Link: https://bit.ly/2UFY02q

2. Margolese HC, Negrete JC, Tempier R, Gill K (2006) A 12-month prospective follow-up study of patients with schizophrenia-spectrum disorders and substance abuse: changes in psychiatric symptoms and substance use. Schizophrenia Research 83: 65-75. Link: https://bit.ly/2xuThIO

3. Batki SL, Leontieva L, Dimmock JA, Ploutz-Snyder R (2008) Negative symptoms are associated with less alcohol use, craving, and " high » in alcohol dependent patients with schizophrenia. Schizophrenia Research 105 201-207. Link: https://bit.ly/2UpGBfk

4. Talamo A, Centorrino F, Tondo L, Dimitri A, Hennen J, et al. (2006) Comorbid substance-use in schizophrenia : relation to positive and negative symptoms. Schizophrenia Research 86: 251-255. Link: https://bit.ly/2WNGYBX

5. Benyamina A (2014) Addictions et comorbidités. Ed. Dunod. Collection: Psychothérapies. Link: https://bit.ly/39pKWDJ

6. Kolliakou A, Castle D, Sallis H, Joseph C, O'Connord J, et al. (2015) Reasons for cannabis use in first-episode psychosis: does strenght of endorsement change over 12 months? European Psychiatry 30: 152-159. Link: https://bit.ly/2wzwziR

7. Thornton LK, Baker AL, Johnson MP, Lewin TJ (2012) Attitudes and perceptions towards substances among people with mental disorders: a systematic review. Acta Psychiatr Scand 126: 87-105. Link: https://bit.ly/2QRO44A

8. Cassidy CM, Lepage M, Mala A (2014) Do motivation deficits in schizophreniasptrum disorders promote cannabis use? An investigation of behavioura response to natural rewards and drug cues. Psychiatric Research 215: 522 527. Link: https://bit.ly/33RnU7h

9. Spencer C, Castle D, Michie PT (2002) Motivations that maintain sunstance use among individuals with psychotic disorders. Schizophrenia bulletin 28 233-247. Link: https://bit.ly/2Jnn1tL

10. Maremmani AGI, Rovai L, Rugani F, Bacciardi S, Massimetti $E$, et al. (2015) Chronology of illness in dual diagnosis heroin addicts: The role of mood disorders. Journal of Affective Disorders 179: 156-160. Link: https://bit.ly/33REzHW

11. Gregg L, Barrowclough C, Haddock G (2009) Development and validation of a scale for assessing reasons for substance use in schizophrenia: The ReSUS scale. Addictive Behaviors 34: 830-837. Link: https://bit.ly/2UoGHnt

12. Gearon JS, Bellack AS, Rachbeisel J, Dixon L (2001) Drug-use behavior and correlates in people with schizophrenia. Addictive Behaviors 26: 51-61. Link: https://bit.ly/2JjCY4f

13. lovieno N, Tedeschini E, Bentley KH, Evins AE, Papakostas GI (2011) Antidepressants for major depressive disorder and dysthymic disorder in patients with comorbid alcohol use disorders: a meta-analysis of placebocontrolled randomized trials. J Clin Psychiatry 72: 1144-1151. Link: https://bit.ly/2vRj8Ku

14. McDonald JL, Meyer TD (2011) Self-Report Reasons for Alcohol Use in Bipola Disorders: Why Drink Despite the Potential Risks?. Clin Psychol Psychother 18 418-425. Link: https://bit.ly/2QSYAbR 
15. Barkus E, Stirling J, Hopkins R, Lewis S (2006) Cannabis-induced psychosis like experiences are associated with high schizotypy. Psychopathology 39 : 175-178. Link: https://bit.ly/2ycGIlL

16. Stirling J, Barkus EJ, Nabosi L, Irshad S, Roemer G, et al. (2008) Cannabis induced psychotic-like experiences are predicted by high schizotypy. Psychopathology 41: 371-378. Link: https://bit.ly/2wHVLna

17. Costain WF (2008) The effects of cannabis abuse on the symptoms of schizophrenia: patient perspectives. Int J Ment Health Nurs 17: 227-235. Link: https://bit.ly/3ar6XDp

18. Buadze A, Stohler R, Schulze B, Schaub M, Liebrenz M (2010) Do patients think cannabis causes schizophrenia? A qualitative study on the causal beliefs of cannabis using patients with schizophrenia. Harm Reduct J 7: 22. Link: https://bit.ly/33TAsel

19. Glaser B, Strauss A (1967) The discovery of Grounded Theory. Chicago: AldineParshotam, R.K. et Joubert, P.M. (2015). Views of schizophrenia patients on the effects of cannabis on their mental health. South African Journal of Psychiatry 22: 57-61.

20. Paillé $P$ (1994) L'analyse par théorisation ancrée. Cahiers de recherche sociologique 23: 147-181. Link: https://bit.ly/2yfdZNi

21. Heatherton TF, Kozlowsk LT, Frecker RC, Fagerstrom KO (1991) The Fagerstrom Test for Nicotine Dependence: a revision of the Fagerstrom Tolerance Questionnaire. Br J Addict 86: 1119-1127. Link: https://bit.ly/3bxKB3g

22. Etter JF, Duc TV, Perneger TV (1999) Validity of the Fagerstrom test for nicotine dependence and of the Heaviness of Smoking Index among relatively light smokers. Addiction 94: 269-281. Link: https://bit.ly/2wLMyKD

23. Saunders JB, Aasland OG, Babor TF, de la Fuente JR, Grant M (1993) Development of the Alcohol Use Disorders Identification Test (AUDIT): WHO. Collaborative Project on Early Detection of Persons With Harmful Alcohol Consumption-II. 88: 791-804. Link: https://bit.ly/3dAeB09

24. Accietto C (2003) La validation d'une version française du questionnaire AUDIT : the Alcohol Use Disorders Identification Test : (PhD n $\left.{ }^{\circ} 10306\right)$. Geneva University.

25. Legleye S, Karila L, Beck F, Reynaud M (2007) Validation of the CAST, a genera population Cannabis Abuse Screening Test. Journal of Substance Use 12 233-242. Link: https://bit.ly/2Jnvi00

26. Legleye S, Piontek D, Kraus L (2011) Psychometric properties of the Cannabis Abuse Screening Test (CAST) in a French sample of adolescents. Drug and Alcohol Dependence 113: 229-235. Link: https://bit.ly/3dKjzaO

27. American Psychiatric Association (2013) Diagnostic and statistical manual (Fifth ed.). Washington, DC: American Psychiatric Association 991. Link: https://bit.ly/3bu2LTp

28. Kolliakou A (2013) Patterns of cannabis use in first-episode psychosis (PhD) London University.

29. Connor JP, Gullo MJ, Feeney GFX, Ross McDY (2011) Validation of the cannabis expectancy questionnaire (CEQ) in adult cannabis users in treatment. Drug and Alcohol Depend 115: 167-174. Link: https://bit.ly/3arjMOI

30. Gregg L, Barrowclough C, Haddock G (2007) Reasons for increased substance use in psychosis. Clin Psychol Rev 27: 494-510. Link: https://bit.ly/33RFGr6

31. Bergeret J (1979) Le toxicomane et ses environnements. Paris, PUF, INSERM $229 p$.

32. Bergeret J (1984) La personne du toxicomane. In: Précis des toxicomanies, Paris, masson 33-105.

33. Cassidy CM, Lepage M, Harvey PO, Malla A (2012) Cannabis use and anticipatory pleasure as reported by subjects with early psychosis and community controls. Schizophr Res 137: 39-44. Link: https://bit.ly/2UNNcPU

34. Green Al, Noordsy DL, Brunette MF, O'Keefe C (2008) Substance abuse and schizophrenia: Pharmacotherapeutic intervention. J Subst Abuse Treat 34: 6171. Link: https://bit.ly/2xrimEG

35. Gupta S, Hendricks S, Kenkel AM, Bhatia SC, Haffke EA (1996) Relapse in schizophrenia: is there a relationship to substance abuse? Schizophrenia Research 20: 153-156. Link: https://bit.ly/33RpuWL

36. Swofford CD, Kasckow JW, Scheller-Gilkey G, Inderbitzin LB (1996) Substance use: a powerful predictor of relapse in schizophrenia. Schizophr Res 20: 145 151. Link: https://bit.ly/33RpHJx

37. Gerding LB, Labbate LA, Measom MO, Santos AB, Arana GW (1999) Alcohol dependence and hospitalization in schizophrenia. Schizophrenia Research 38 71-75. Link: https://bit.ly/39iyxRS

38. Ameller A, Gorwood P (2015) Poids de la comorbidité addictive dans le risque d'observance partielle au traitement médicamenteux et de rechute dans la schizophrénie. L'Encéphale 41: 174-183. Link: https://bit.ly/39olX2f

39. Hardeman SM, Harding RK, Narasimhan M (2010) Simplifying Adherence in Schizophrenia. Psychiatr Serv 61: 405-408. Link: https://bit.ly/2xt3ipW

40. Pringuey D, Papetti F, Cherikh F, Tible O (2009) Vulnérabilité et trouble mental. Vie sociale 1: 93-101. Link: https://bit.ly/3bxNQaY

41. Gaudriault P, Joly V (2013) Construire la relation thérapeutique. Ed. Dunod. Link: https://bit.ly/2QRUUXN

42. Acier D (2016) Les addictions. Ed. De Boeck Université. Collection : Le point sur. Link: https://bit.ly/2QLIYXJ

43. Favrod J, Gibellini Manetti S, Rexhaj S, Crespi Balemi S, Conus P, et al. (2013) Effet des groupes motivationnels pour les personnes atteintes de psychose qui consomment du cannabis. L'Évolution Psychiatrique 78: 97-106. Link: https://bit.ly/2WQ2sOA

44. Sharma R, Lodhi S, Sahota P, Thakkar MM (2015) Nicotine administration in the wake-promoting basal forebrain attenuates sleep-promoting effects of alcohol. J Neurochem 135: 323-331. Link: https://bit.ly/3bu4at9

45. Salyers MP, Mueser KT (2001) Social functioning, psychopathology and medication side effects in relation to substance use and abuse in schizophrenia. Schizophr Res 48: 109-123. Link: https://bit.ly/39sMtJ0

46. Morel A, Couteron JP, Fouilland P (2015) Aide-mémoire Addictologie en 49 notions (2nde édition). Paris, France: Editions Dunod. Link: https://bit.ly/2vU8Fhs

47. Petitjean F (2011) Les effets de la psychoéducation. Annales Médico-Psychologiques. Revue Psychiatrique 169: 184-187. Link: https://bit.ly/39vwSbT

48. Bourgeois ML, Benezech M, Antoniol B, Haustgen T (2011) Discernement, lucidité, conscience et insight en psychopathologie et en pratique expérimentale. Annales Médico-Psychologiques 169: 433-437. Link: https://bit.ly/33T1ZwH

49. Masson M, Azorin JM, Bourgeois ML (2001) La conscience de la maladie dans les troubles schizophréniques, schizo-affectifs, bipolaires et unipolaires de l'humeur: résultats d'une étude comparative de 90 patients hospitalisés. Annales Médico-psychologiques, revue psychiatrique 159: 369-374. Link: https://bit.ly/2UFudXG

50. Aarab C, Elghazouani F, Aalouane R, Rammouz I (2015) Facteurs de risque de l'inobservance thérapeutique chez les patients schizophrènes: étude cas- témoins. The Pan African Medical Journal 20: 273. Link: https://bit.ly/3bxQJZ4

51. Lançon C, Aghababian V, Richieri R, Boyer L, Simenoni MC, et al. (2011) Insight 
et qualité de vie subjective chez les personnes souffrant de schizophrénie. Annales Médico-Psychologiques. Revue Psychiatrique 169: 429. Link: https://bit.ly/3arOZju

52. Aghababian V, Auquier P, Baumstarck-Barrau K, Lançon C (2010) Influence des troubles de la conscience sur l'autoévaluation de la qualité de vie des patients souffrant de schizophrénie. L’Encéphale 5: 25-29.

53. Antonovsky A (1993) The structure and properties of the sense of coherence scale. Social Science and Medicine 36: 725-733. Link: https://bit.ly/39mFbqk
54. Charpentier A, Goudemand $M$, Thomas $P$ (2009) L'alliance thérapeutique, un enjeu dans la schizophrénie. L'Encéphale 35: 80-89. Link: https://www.em-consulte.com/en/article/202145

55. Roncero C, Daigre C, Gonzalvo B, Valero S, Castelles X, et al.. (2013) Risk factors for cocaine-induced psychoses in cocaine-dependent patients. Eur Psychiatry 28: 141-146. Link: https://pubmed.ncbi.nlm.nih.gov/22118812/

\section{Discover a bigger Impact and Visibility of your article publication with}

Peertechz Publications

\section{Highlights}

* Signatory publisher of ORCID

* Signatory Publisher of DORA (San Francisco Declaration on Research Assessment)

* Articles archived in worlds' renowned service providers such as Portico, CNKI, AGRIS, TDNet, Base (Bielefeld University Library), CrossRef, Scilit, J-Gate etc.

* Journals indexed in ICMJE, SHERPA/ROMEO, Google Scholar etc.

* OAI-PMH (Open Archives Initiative Protocol for Metadata Harvesting)

* Dedicated Editorial Board for every journal

* Accurate and rapid peer-review process

* Increased citations of published articles through promotions

* Reduced timeline for article publication

\section{Submit your articles and experience a new surge in publication services}

(https://www.peertechz.com/submission).

Peertechz journals wishes everlasting success in your every endeavours.

Copyright: @ 2020 Para BG, et al. This is an open-access article distributed under the terms of the Creative Commons Attribution License, which permits unrestricted use distribution, and reproduction in any medium, provided the original author and source are credited. 